\title{
Effects of Pollution on Human Growth and Development: An Introduction
}

\author{
Lawrence M. Schell, Mia V. Gallo, Melinda Denham and Julia Ravenscroft \\ University at Albany, Albany, New York, USA
}

\begin{abstract}
Pollution is a worldwide problem and its potential to influence the physiology of human populations is great. Studies of human growth and development in relation to pollution have increased in number and quality since the mid-twentieth century. Many studies have found that some pollutants have detrimental effects on human growth, particularly prenatal growth. The heavy metal, lead, is commonly found in human populations and is related to smaller size at birth and studies have reported decrements that range up to about 200 grams. Noise stress from transportation sources also is related to reduced prenatal growth with somewhat smaller decrements reported. Studies of humans exposed to polychlorinated biphenyls, one of the persistent organic pollutants, have reduced size at birth, advanced sexual maturation and altered hormone levels related to thyroid regulation. Thus different pollutants exert effects through different physiological pathways. However, some studies have not observed these effects, which indicates that the situation is complex and requires further study with better study designs. Determining the effects of pollutants on human physiology and growth is difficult as it requires fairly large numbers of subjects who are not purposely exposed but for whom exposure can be measured. These effects of pollutants and the mechanisms of effect require further study to understand and, it is hoped, to blunt or block any detrimental effects on human health and well-being. J Physiol Anthropol 25(1): 103-112, 2006 http://www.jstage.jst.go.jp/browse/jpa2
\end{abstract}

[DOI: 10.2114/jpa2.25.103]

Keywords: PCBs, polychlorinated biphenyls, lead, noise, infants, children, growth, menarche, persistent organic pollutants

\section{Introduction}

Pollution is defined as a material or a form of energy that is unwanted, usually because it is believed to be detrimental to health and well-being. Pollution can be made by human activity and by natural forces as well. Human exposure to pollution is believed to be more intense now than at any other time in human existence.

Understanding the effects of pollution on human physiology and populations is difficult because it is unethical to expose human subjects to materials or energy that could be harmful, animal models are not exact duplicates of human responses, and the variety of effects that could be studied is large. The study of human growth provides a good indication of the harmfulness of pollutants because growth is the result of many physiological pathways and is the outcome of many processes that can be deranged by environmental influences, including pollutants. The precedent for this approach is clear. Johnston has said that growth is ecosensitive (Johnston, 1993, 1995; Johnston and Low, 1995), and Tanner has promoted the idea that patterns of growth can be studied to determine where conditions of society are not meeting basic biological needs of children (Tanner, 1978, 1986). The premises and advantages of auxological epidemiology, which is the name for the study of growth to determine adverse environmental influences, have been described before (Schell et al., 1992; Schell, 1997). The most common research design used for studies of human growth, including those in auxological epidemiology, is the observational design.

\section{Research Designs: Experimental and Observational.}

Research in physiological anthropology is often conducted using study designs that can be categorized as experimental. Subjects are assigned to study groups, if possible by random assignment, some intervention is applied to some of the groups, perhaps an exposure or test, and a comparison is made. However, much of the work determining the relationships between environmental variables and the patterns of human growth and development proceed with observational designs that are common in epidemiology and population biology. Rarely are experiments conducted to determine these relationships primarily because it would be unethical to expose children or developing fetuses to environmental factors that are thought to be harmful. Using the terminology of epidemiologists to describe scientific study designs, we would say that most often an observational study design is used. In observational studies the investigator compares groups of people that are formed by 
their own choice, for example cigarette smokers vs. nonsmokers, and without his intervention (Lilienfeld and Stolley, 1994). This design produces statistical measures of association between variables but cannot establish a cause and effect relationship on its own because the variables have not been manipulated. Furthermore, the groups are not randomly selected and this creates a question of whether the results from the study can be generalized to the population as a whole.

The usual way epidemiologists and other population biologists assess the causal basis of statistical associations between variables in a population is by determining if evidence answers the following questions (termed Hill's criteria (Lilienfeld and Stolley, 1994)): 1) Is the relationship biologically plausible? 2) Is the relationship replicated and consistent across studies? 3) Is the relationship consistent across sub-groups? 4) Does the relationship exhibit a doseresponse curve? 5) Does the relationship exhibit proper temporal sequence? When studies of the same problem can address these criteria, we are able to assess whether the statistical association is likely to be based on a causal connection between variables. However, rarely are all five criteria met, often because there are an insufficient number of research studies on a subject. For a few pollutants it is possible to conduct this evaluation although most often the evaluation is incomplete. Nevertheless doing so allows us to see what kinds of studies should be conducted in order to complete the criteria.

\section{Noise Exposure and Human Growth}

A good example with which to begin is the relationship between noise exposure and human prenatal and postnatal growth. To assess whether a relationship is biologically plausible we may consider studies of laboratory animals exposed to noise. Non-human animal studies have established that noise is a stressor (Busnel, 1978; Cohen and Weinstein, 1981; DeJoy, 1984; Geber et al., 1966; Geber, 1973; Glorig, 1971; Herrington and Nelbach, 1942; Ishi and Yokobori, 1960; Iturrian and Fink, 1968; Welch and Welch, 1970). Furthermore, several laboratory studies have shown that animal growth is inhibited by noise exposure (Michaud et al., 2005). It is most likely that stress affects growth through the endocrine system. Noise stress activates the hypothalamicpituitary-adrenal axis, and stress has growth-inhibiting effects possibly through the action of corticosteroids, but also through other pathways as well. Determining whether noise produces stress in humans and can affect human growth requires a natural laboratory, and noisy airport communities can be that laboratory.

Many studies of airport communities have found evidence of stress in adults and in children, and found decrements in growth associated with noise exposure. There is ample laboratory work to show that noise is a stressor among adults, including women of childbearing age. Ando and Hattori (1977) showed that pregnant women exposed to airport noise had lower placental lactogen levels. Research on noise stress in children is rare. However, Evans and colleagues (1998) studied epinephrine levels in children in two communities: one was near an airport outside Munich and the second was a control community. Epinephrine levels during the 6 months before the airport was used are lowest, and levels in the 6 and 18 months following completion of the airport are significantly higher. In the community near the airport, epinephrine levels rose following completion of the airport, but in the control community, there was no increase in levels. This suggests that the airport traffic stimulated a fundamental component of the stress response, and it is consistent with the laboratory experiments with non-humans that have shown that noise is a classic stressor. Importantly it shows that airport noise is a stressor and it is a stressor among children. Thus, there is a biologically plausible pathway for reduced growth in response to noise.

Birth weight has been shown in several studies to be reduced in relation to noise exposure from airports and other sources. In work done with a population near Amsterdam, birth weights were reduced (Knipschild et al., 1981). Here there is some control for socioeconomic status, which is usually a large influence on birth weight. The effect is found in both income groups but really only in females. However, this study did not control for other variables that affect birth weight, such as cigarette smoking. Other studies have produced similar results (for review see Schell, 1982), and have controlled for other influences on birth weight including parental sizes, maternal characteristics such as weight gain during pregnancy, smoking, education, income, and gestation length (Schell, 1984) (Fig. 1). Some studies show an effect more prominently in females than males (Ando, 1988; Coblentz et al., 1990; Knipschild et al., 1981; Schell, 1982). Thus, there is some consistency among studies (see also Hartikainen et al., 1994; Kawada, 2004; Zhan et al., 1991), but not all studies have found reduced birth weight (Hartikainen-Sorri et al., 1991; Wu et al., 1996).

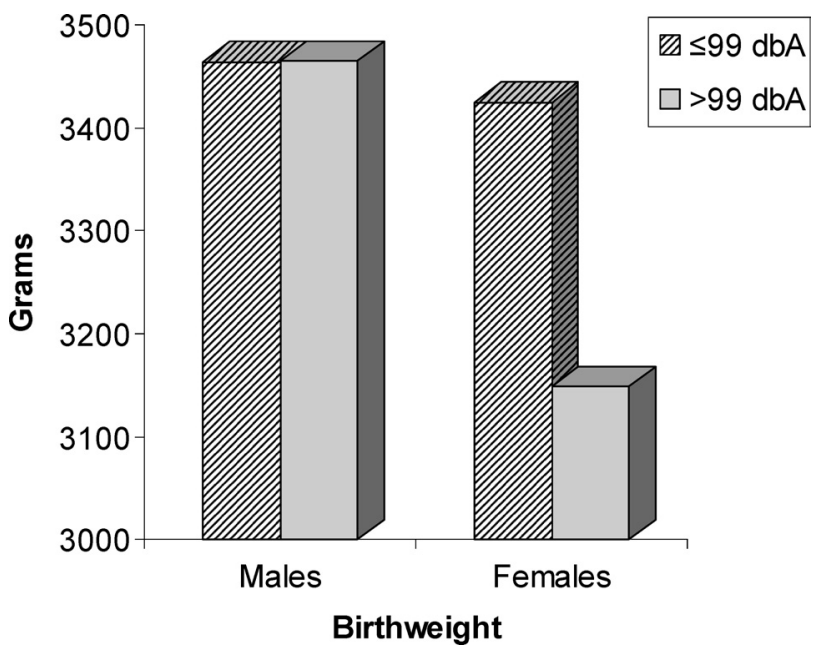

Fig. 1 Adjusted mean birth weights stratified by sex of two different aircraft noise exposure groups after statistic adjustment for control variables (adapted from Schell, 1984). 
Turning to criterion of dose-response relationship, Ando and Hattori (1973) in Itami City, Japan analyzed data on over a thousand births. In the control cities the rate of low birth weight was slightly less than $6 \%$ while in the high noise exposure cities it reached $8.5 \%$, a statistically significant difference. Ando and Hattori categorized births into five groups based on noise exposure, and frequency of low birth weight increases fairly consistently with noise exposure, demonstrating a rough dose-response relationship in these results.

Temporal sequence, where the putative cause precedes in time the biological effect is difficult to demonstrate in observational studies, but there is evidence from a natural experiment created when jet planes were introduced at an airport in Japan (Ando, 1988). This shows the temporal sequence that is lacking in most other studies. Here is a situation where changes in jet plane traffic caused an increase in noise exposure around the airport. Jet plane traffic at this particular airport began between 1963 and 1964. The rate of low birth weight babies, defined here as below 3000 grams, before jet plane traffic began was less than the national average in Japan in 1961, 1962 and 1963. As soon as jet plane traffic began and as it increased, the rate of low birth weight increased, and after a few years the rate of low birth weight became substantially higher than the national average. The sequence of cause and effect is demonstrated in these data (see Schell and Denham, 2003).

In summary, there is substantial evidence for an effect of noise on human prenatal growth. Most of the criteria that were developed by epidemiologists to evaluate observational studies for evidence of causality are met. However, some studies have not seen a relationship, and this suggests that other variables must be studied as well. Studies on postnatal growth are rare (Schell and Hodges, 1985; Schell and Norelli, 1983; Takahashi and Kyo, 1968) and insufficient to reach a firm conclusion.

\section{Persistent Organic Pollutants: Polychlorinated Biphenyls}

Persistent organic pollutants (POPs) are a group of compounds produced purposely or accidentally by industrial processes. They include a variety of pesticides and herbicides such as hexochlorobenzene (HCB), mirex, 1,1,1-trichloro-2,2bis( $p$-chlorophenyl)ethane (DDT), polychlorinated biphenyls (PCBs) and polybromated biphenyls (PBBs), and dioxin (2-37-8 tetrachlorodibenzo- $p$-dioxin, (TCDD)). They are lipophilic and are concentrated in adipose tissue. They bioaccumulate up the food chain and many are metabolized slowly over years and decades. Breast milk contains concentrated POPs. One of the most terrible human exposures to PCBs occurred through contaminated rice oil in the Fukuoka Prefecture, Japan in 1968. The disease, termed Yusho, was subject to much study and the studies showed that growth was affected to some extent (Aoki, 2001; Kuratsune, 1976; Masuda, 2001; Murai et al., 1987; Yoshimura, 1974). Research on growth of Yusho children and of children born to Yusho mothers has been summarized previously (Schell, 1991, 1999; Schell and Denham, 2003).

After the Yusho poisoning, another mass poisoning occurred in Taiwan in 1979, termed Yu-cheng, and investigators observed many of the same health problems (Chen et al., 1992; Guo et al., 1994, 1995; Yen et al., 1989, 1994). After the Yusho poisoning, scientists have investigated many populations for the presence of PCBs and other POPs, and have discovered low levels of POPs in all populations studied, even in very remote arctic populations in North America (Tenenbaum, 1998). This raises the question whether the effects seen in Yusho and Yucheng may occur in people at lower levels of exposure also. Exposure to POPs is extensive because they have entered the food chain and are very persistent. Most human exposure is through ingestion of fish, meat, eggs and dairy products including milk and butter. Because POPs are lipophilic and bioaccumulate, they are concentrated in animals that consume other animals or that are fed fats from other animals. Thus, cattle and farm raised salmon may have higher levels of POPs than free-living populations, and free-living animals high on the food chain such as whale, walrus, and polar bear, may carry high levels of POPs. In addition, POPs are transferred from mother to fetus across the placenta, and from mother to infant through lactation. POPs also can be absorbed through the dermis, and inhalation is an additional route of exposure. POPs can be carried from industrial areas by winds high aloft to remote areas such as the Arctic and contaminate food there.

Many PCBs are very persistent in the environment and can resist metabolism leading to long-term storage in fat tissue. These properties depend on the form of the molecule. PCBs can take a large variety of forms, or congeners, depending on how many carbons are substituted with chlorines and where the substitutions occur. Some congeners of PCBs persist in people and the environment for decades.

Some PCB congeners have patterns of chlorines that cause them to resemble dioxin (Fig. 2), one of the most toxic substances known. This suggests that the effects of some PCB congeners, particularly ones lacking chlorines in the ortho positions, may resemble dioxin's effects (Carpenter, 1998; Safe, 1994). In general, PCBs are suspected of causing a wide variety of physiological changes that may in turn contribute to health problems involving the endocrine, reproductive, immune, nervous and cardiovascular systems.

To investigate the effects of low-level exposure to PCBs and other toxicants, we began a study of Mohawk Indian youth 10-16.9 years of age. The youth were all members of the Akwesasne Mohawk Nation. The Nation straddles the St. Lawrence River and occupies territory in New York State (US), and in Quebec and Ontario (Canada). Exposure at Akwesasne occurred when industries located on the St. Lawrence River in the 1950s contaminated the environment with PCBs through improper disposal practices. Fish and game absorbed the PCBs. Customary food sources for the Akwesasne community include locally caught fish, and ingestion of fish was a major route of exposure for adults and children. Newborns were 

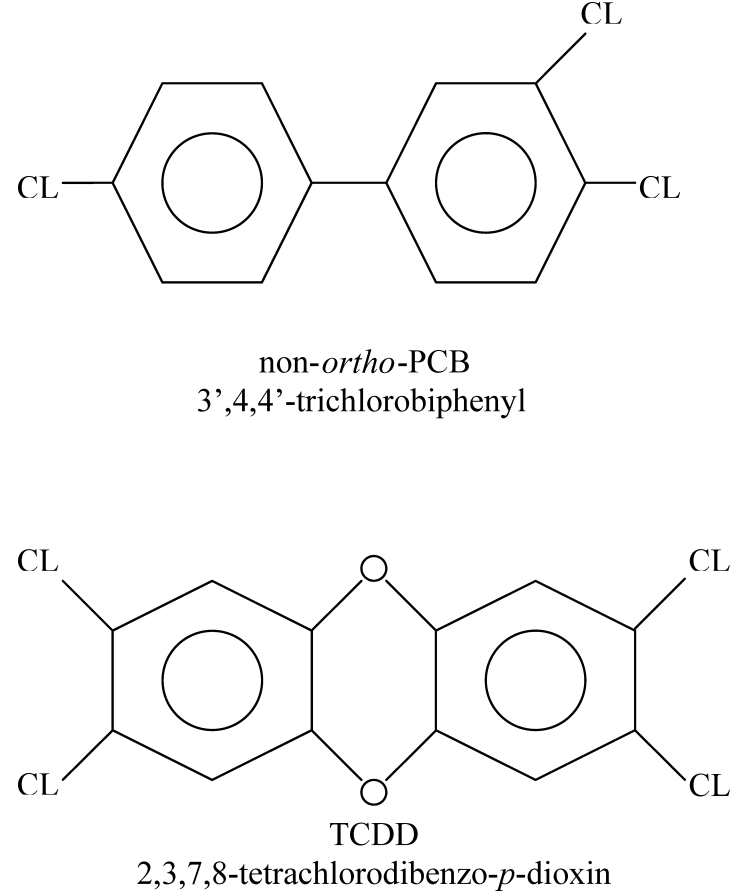

Fig. 2 Molecular structure of a non-ortho PCB and dioxin. Note the ability of the PCB molecule to form a planar configuration like the TCDD molecule.

exposed prenatally to PCBs in mother's circulation, and then through lactation. Postnatal exposure also occurred through the consumption of contaminated fish and game. In the mid-1980s local and state departments of health advised the population to avoid consumption of locally caught fish, and levels of PCBs have fallen since then (Fitzgerald et al., 1998, 1999). However, persistent PCBs remain in adults and children at Akwesasne, although at levels lower than occurred in Yusho poisoning.

Our research at Akwesasne includes investigation of growth and maturation, levels of sex steroids and thyroid hormones, as well as cognitive and behavioral characteristics. The 10-16.9 year age range of participants allowed the study of growth during a period of rapid growth, as well as sexual maturation including changes in sex steroids while having relatively constant levels of thyroid hormones. Participants were sufficiently mature to follow instructions for sensitive testing of cognition and behavior. This holistic approach involves the collection of a great deal of data and some of these data have been analyzed.

The methods of data collection have been described previously (Schell et al., 2003, 2004), and will be described here in brief. Families were contacted by Mohawk community researchers to solicit participation of children in the appropriate age range. All participants had blood drawn in the morning on rising to insure that samples would not be affected by diurnal variation, and following an overnight fast to insure that recent food consumption would not affect toxicant levels. Ultratrace congener specific analysis of PCBs allowed the separation of 83 peaks, including 101 congeners as singles,

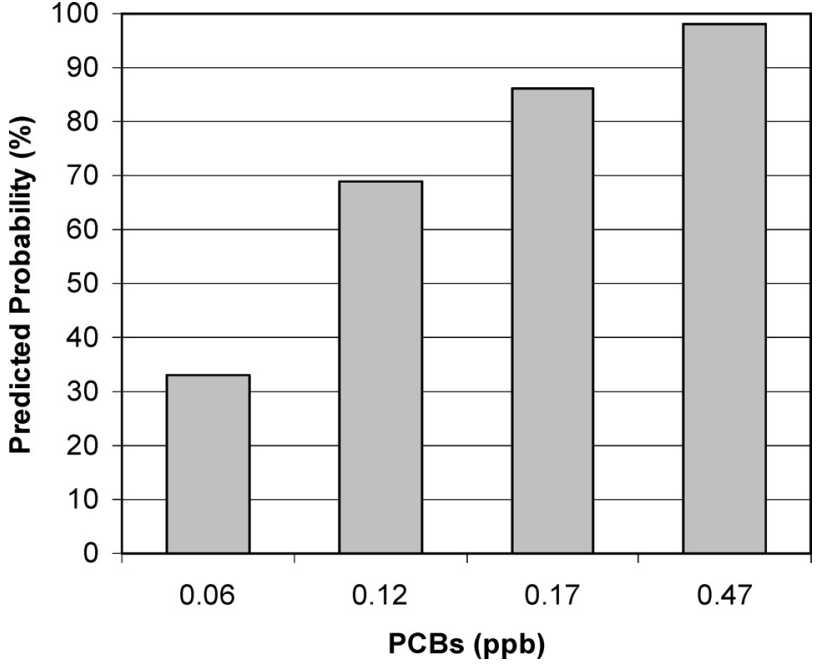

Fig. 3 The predicted probability of 12-year-old Akwesasne Mohawk girls having reached menarche at different levels of a group of estrogenic PCBs (adapted from Denham et al., 2005).

doubles or triplets (DeCaprio et al., 2000). In addition, we obtained measurements of $p, p^{\prime}$-DDE (the primary metabolite of DDT), mirex, HCB, as well as lead and mercury. After blood was drawn, a full anthropometric examination was conducted. Sexual maturation in terms of Tanner Stages was assessed by having the participant compare simple sketches of the five stages with themselves, and choosing the one sketch that was most like them. Girls were asked if they had reached menarche (yes/no). The participant was interviewed to learn of family characteristics and diet. In cases where the child was less than 13 years of age, the mother was interviewed to assess the child's diet.

We have examined the effect of several pollutants, including PCBs, on the timing of menarche (Denham et al., 2005). We performed probit and logit analyses on presence or absence of menarche. In our analysis we found that menarche was more likely to have occurred among same-aged girls with higher PCB burdens. Furthermore, these associations were specifically seen for a group of four potentially estrogenic PCB congeners, but were not found when tested with groups of antiestrogenic or enzyme-inducing congeners (Denham et al., 2005). At the lowest level of the estrogenic PCB group, 33\% of 12-year-old Mohawk girls were predicted to have reached menarche when controlling for socioeconomic status and other toxicant burdens (lead, mercury, HCB, $p, p^{\prime}$-DDE, mirex), whereas at the geometric mean $69 \%$, and at the highest PCB value $98 \%$ of 12 -year-old girls were predicted to have reached menarche (see Fig. 3). This effect was observed among girls with toxicant burdens comparable to other populations exposed at background levels.

We also have examined the relationship of toxicants to levels of thyroid hormones. Thyroid hormones are essential for maintaining normal rates of metabolism, growth and development, and cognitive performance. Our initial analysis of 115 boys and girls indicated that some PCBs were related to 
thyroid hormones and activity. A group of the more highly chlorinated PCB congeners was positively and significantly associated with thyroid stimulating hormone (TSH) and was negatively associated with thyroxine. These results were observed in a multivariale analysis controlling for other variables, such as blood lipids and other toxicants (Schell et al., 2004). A high level of TSH is diagnostic of hypothyroidism. Although we did not find a significantly elevated occurrence of this disease, we did find a shift in the distribution of TSH indicating that PCBs had affected thyroid physiology in this population. Higher TSH levels in conjunction with lower levels of thyroxine and free thyroxine suggest that the hypopituitary thyroid axis is functioning to maintain normal thyroid gland activity and related functions. Other toxicants were not so clearly related to thyroid hormones or TSH.

Although we have described the pattern of physical growth at Akwesasne (Gallo et al., 2005), we have not yet tested the relationship between toxicants and growth. However, several other studies have examined the relationship between POPs, particularly PCBs, and growth. Most of these have examined size at birth; while studies of postnatal growth are far fewer. Many of these studies have examined the effects of maternal consumption of fish contaminated with PCBs and other toxicants.

In general, these studies indicate that prenatal exposure to PCBs can cause lower birth weight and shorter gestation. The decrease in birth weight ranges from 22 to $500 \mathrm{~g}$ (Baibergenova et al., 2003; Fein et al., 1984; Karmaus and Zhu, 2004; Rylander et al., 1996, 2000; Taylor et al., 1984, 1989). The strongest evidence to date comes from a cohort of mothers and offspring who consumed fish from Lake Michigan. Neonates with cord serum levels of $5.0 \mathrm{ng} / \mathrm{ml}$ or more had decreased birth weight of approximately 160-190 g, and smaller head circumference compared to lower exposed children (Fein et al., 1984). A study of infants in the Netherlands found lower birth weight ( $\sim 165 \mathrm{~g}$ less) and delayed growth were correlated with higher PCB levels measured in cord plasma and mother's blood (Patandin et al., 1997, 1998). A recent study of Great Lakes fish eaters on the effect of PCBs and $p, p^{\prime}$-DDE on birth weight found a significant decrease $(\sim 500 \mathrm{~g})$ in birth weight of infants born to mothers with PCB levels of $25 \mu \mathrm{g} / \mathrm{L}$ or more (Karmaus and Zhu, 2004). To insure that mismeasurement of smoking status did not affect the results, the authors also investigated the effects of PCBs on birth weight in just the non-smoking participants. They found a reduction in birth weight in the nonsmoking group associated with low levels of PCB exposure $(<5 \mu \mathrm{g} / \mathrm{dL})$.

Adverse effects of environmental pollutants on postnatal growth have been convincingly documented in poisoning episodes (Guo et al., 1993, 1995) however, reports on the effect of background or chronic exposure to toxicants on physical growth in children and adolescents are inconsistent and incomplete. We hope that analysis of our data may clarify the situation with regard to toxicants and adolescent growth and development.
In summary, the data on PCBs reported to date suggest that the greatest risks to development are associated with exposure during the prenatal period. The effects reported on growth postnatally suggest possible impairment during a critical period of neuroendocrine or other central nervous system development.

\section{Lead and Human Growth}

Lead is a ubiquitous pollutant in industrialized countries and it has no known benefits for human physiology or performance. The primary sources of lead in the environment are auto emissions from leaded fuel, industrial emissions and lead-containing paint that is flaking into the environment. The usual pathways of lead exposure among humans are described in Fig. 4. Most lead enters the body by ingestion rather than inhalation, and levels of lead in the blood rise from birth to a peak at approximately two to three years of age unless there is an occupational exposure in adult life. Lead that is absorbed into the blood stream reaches every organ, but is stored in the skeleton such that among adults, approximately $90 \%$ of the body's lead burden is found in the skeleton where it can pass back into the bloodstream. Although the problem of lead in children has received a great deal of attention in the US, there are many countries where blood lead levels in children are just as high or are higher than in the US.

The effects of lead vary with the amount and timing of exposure. The US Centers for Disease Control and Prevention has described the effects (Fig. 5) that range from death at high doses to neurobehavioral deficits and growth impairment at low ones (ATSDR, 1988).

Effects on growth have been reported in numerous studies, but not by all investigations. Results from studies of lead and birth weight that were conducted prior to 1999 have already been described (Schell, 1999; Schell and Knutson, 2002). In general, many studies have found a negative association between lead level in the mother or in the newborn, and the weight of the baby. However not all studies have seen this relationship and the reasons for the variation in results has been studied in detail, but not fully explained (Andrews et al., 1994). Studies conducted since these reviews have shown small, but fairly consistent decrements in weight at birth in relation to greater lead levels (Bellinger, 2005; HernandezAvila et al., 2002; Kaul et al., 2002; Odland et al., 1999; Osman et al., 2000; Srivastava et al., 2001; Uryu et al., 2004). Even maternal blood lead levels as low as $0.06 \mu \mathrm{mol} / \mathrm{L}$ predicted a reduction in birth weight by approximately $100 \mathrm{~g}$ (Odland et al., 1999). Hernandez-Avila et al. (2002) reported an increased risk of having a lower birth length $(\mathrm{OR}=1.03)$ and a smaller head circumference $(\mathrm{OR}=2.13)$ with increasing bone lead levels.

There are far fewer studies of postnatal growth and lead (Schell, 1999; Schell and Knutson, 2002). This is probably because in most countries size during childhood is not routinely measured with much accuracy or precision. Therefore, in order 


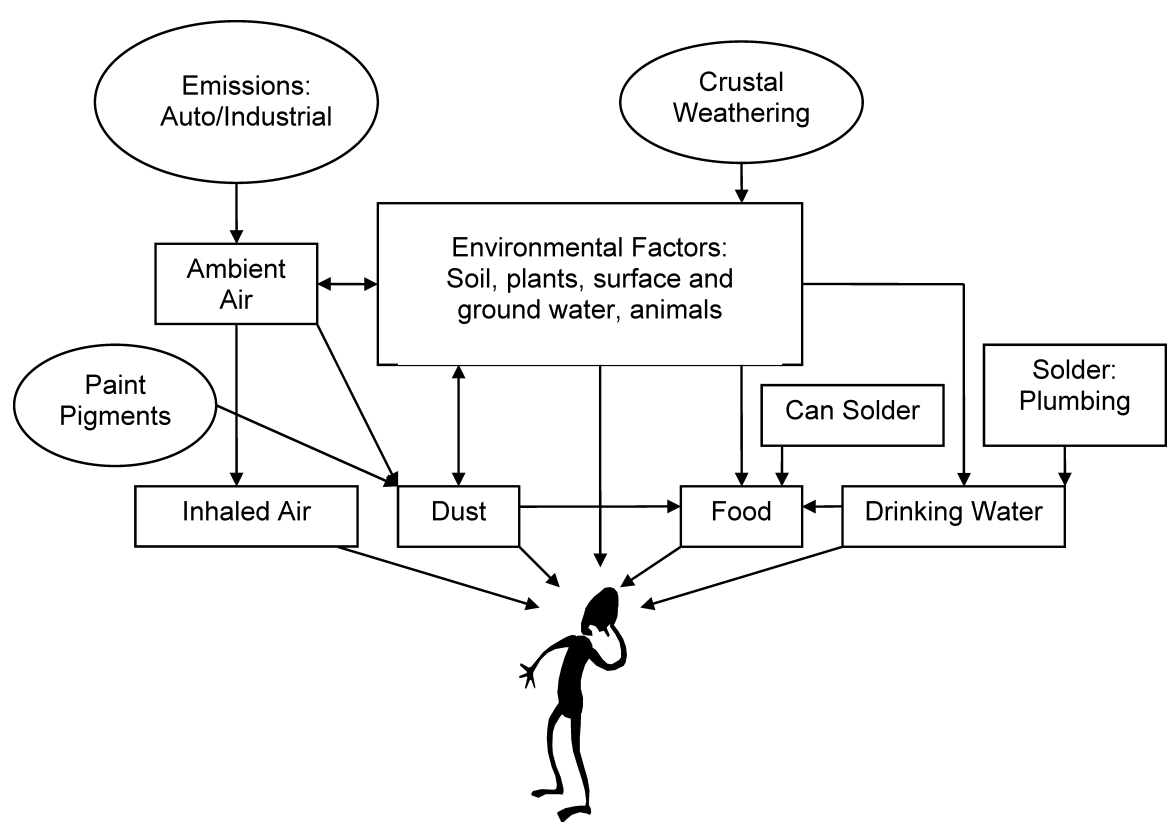

Fig. 4 Pathways of human exposure to lead.

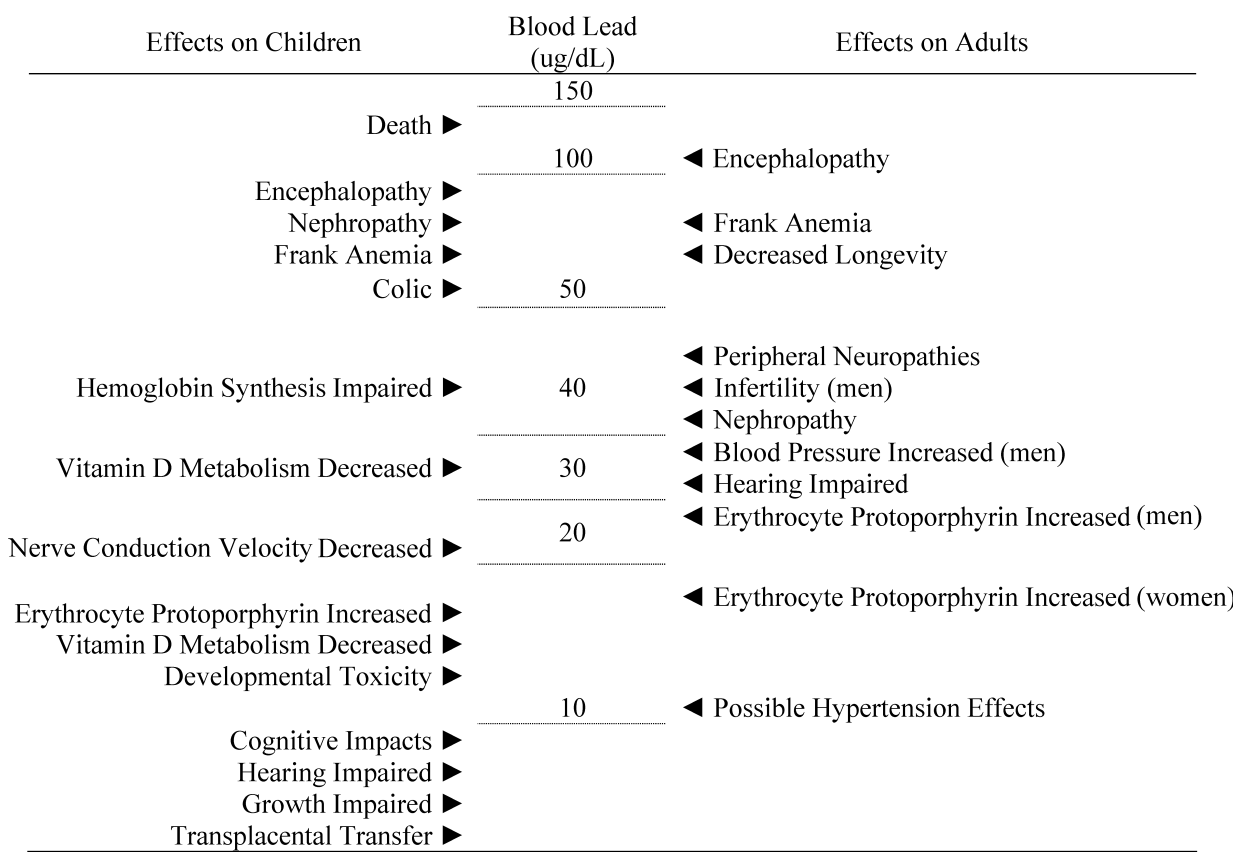

Fig. 5 Lowest observable effects of blood lead levels (Adapted from ATSDR, 1989).

to relate size to blood lead levels, records cannot be used and children must be measured; this is an expense in addition to measuring the blood lead levels.

There have been three large studies of lead and childhood growth in the US. All three studies used data compiled by the US National Center for Health Statistics. These data sets comprise representative samples of US children, and a large variety of information was collected and is included in the data sets including anthropometry and blood lead levels. All three studies have shown that children with higher lead levels have a small but statistically significant decrement in height. The most recent of these using data from NHANES III found an approximately $1.6 \mathrm{~cm}$ reduction in stature for each $10 \mu \mathrm{g} / \mathrm{dL}$ of lead among non-Hispanic children 1-7 years of age and the effect is present in both boys and girls (Ballew et al., 1999). This finding is consistent with the two earlier studies. A NHANES II study reported a $1.5 \%$ reduction in height, weight, and chest circumference in children with greater than the sample mean blood lead level at 59 months (Schwartz et al., 1986). Another study found a $1.2 \mathrm{~cm}$ stature reduction among 
1,400 Mexican American boys and girls 5-12 years of age with lead levels greater than the sample median (Frisancho and Ryan, 1991). Most of these studies have had good statistical control over other factors related to size, including diet. Mechanisms of effect are not yet known; although a study of a clinically growth-depressed sample showed deranged growth hormone levels and regulation (see for review Schell, 1999).

Recent studies in the US have revealed that sexual maturation may be affected by lead. Using a national probability sample of US children, two different teams of investigators discovered that at higher lead levels girls were less likely to have attained menarche (Wu et al., 2003) and age at menarche was delayed by approximately three and a half months (Selevan et al., 2003). It seems likely that lead has the capacity to disrupt the endocrine system, either during the period of rapid sexual maturation during adolescence, or during the prenatal period leading to delayed effects on human physiology.

Our group has worked with a community of Mohawk Indians to learn of the effects of exposure to polychlorinated biphenyls. In performing this study we also examined the effects of lead on growth and development, including age at menarche (Denham et al., 2005). Our analysis of these data showed that menarche was substantially delayed in relation to lead levels. As lead levels increase, the odds of reaching menarche decreased significantly, even after controlling for age, socioeconomic status and other toxicant burden (mercury, PCBs, HCB, $p, p^{\prime}$-DDE, and mirex). At the geometric mean of lead, $69 \%$ of 12 -year-old girls were predicted to have reached menarche, compared to only $10 \%$ at the 75 th percentile of lead (see Fig. 6). This effect was observed even though the levels of lead in the blood were low. None of the youth had a level of lead in the blood that the US Centers for Disease Control and Prevention believes has an impact on human health.

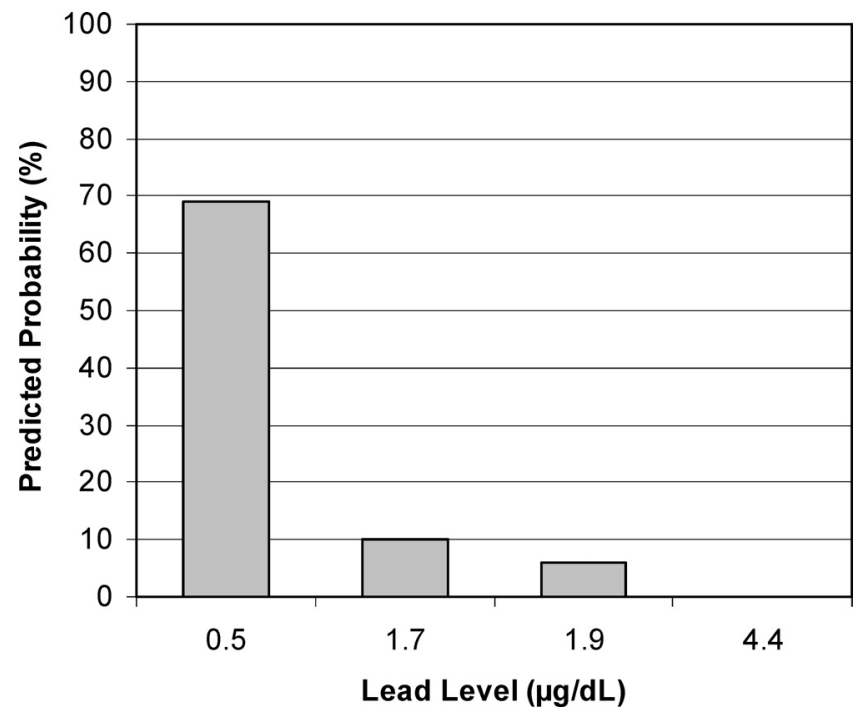

Fig. 6 The predicted probability of 12-year-old Akwesasne Mohawk girls having reached menarche at different blood lead levels (adapted from Denham et al., 2005).

\section{Summary and Conclusion}

Many studies of pollution and human growth have reported changes in growth or maturation patterns in relation to one or several pollutants. These changes seem to be caused by changes in the underlying physiology of growth. However, the effects of pollutants on human physiology, growth and development are not known comprehensively. Furthermore, pollution is a growing problem worldwide as more countries industrialize and some industrialized countries resist control of this problem. Therefore, it is likely that the effects of pollution on the human species will be a problem for many years. However, determining the effects of pollutants on human physiology and growth is difficult. Human populations are exposed to many different pollutants simultaneously making it difficult to separate effects of each pollutant. Furthermore, studies require fairly large numbers of participants who cannot be purposely exposed, but who should have accurate measurement of exposure. Nevertheless, effects of pollution should be subject to intensive investigation to learn the extent of the problem, its probable consequences, and ways to block the effects of pollution on human health and well-being.

Acknowledgments We are pleased to acknowledge the encouragement of Douglas Crews in organizing the meeting and this group of articles.

\section{References}

Agency for Toxic Substances and Disease Registry (ATSDR) (1988) The nature and extent of lead poisoning in children in the United States: A report to Congress. US Department of Health and Human Services, Public Health Services, Atlanta

Agency for Toxic Substances and Disease Registry (1989) Toxicological profile for lead. US Department of Health and Human Services, Public Health Services, Atlanta

Ando Y (1988) Effects of daily noise on fetuses and cerebral hemisphere specialization in children. J Sound Vib 127: 411-417

Ando Y, Hattori H (1973) Statistical studies on the effects of intense noise during human fetal life. J Sound Vib 27: 101110

Ando Y, Hattori H (1977) Effects of noise on human placental lactogen (HPL) levels in maternal plasma. Br J Obstet Gynaecol 84: 115-118

Andrews KW, Savitz DA, Hertz-Picciotto I (1994) Prenatal lead exposure in relation to gestational age and birth weight: A review of epidemiologic studies. Am J Ind Med 26: $13-32$

Aoki Y (2001) Polychlorinated biphenyls, polychlorinated dibenzo-p-dioxins, and polychlorinated dibenzofurans as endocrine disrupters - what we have learned from Yusho disease. Environ Res 86: 2-11

Baibergenova A, Kudyakov R, Zdeb M, Carpenter DO (2003) 
Low birth weight and residential proximity to PCBcontaminated waste sites. Environ Health Perspect 111: 1352-1357

Ballew C, Khan LK, Kaufmann R, Mokdad A, Miller DT, Gunter EW (1999) Blood lead concentration and children's anthropometric dimensions in the Third National Health and Nutrition Examination Survey (NHANES III) 1988-1994. J Pediatr 134: 623-630

Bellinger DC (2005) Teratogen update: lead and pregnancy. Birth Defects Res A Clin Mol Teratol 73: 409-420

Busnel MS (1978) Preliminary results of the effects of noise on gestating female mice and their pups. In Fletcher JL, Busnel RG eds. Effects of Noise on Wildlife. Academic Press, New York, 209-248

Carpenter DO (1998) Polychlorinated biphenyls and human health. Int J Occup Med Environ Health 11: 291-303

Chen YCJ, Guo YL, Hsu CC, Rogan WJ (1992) Cognitive development of Yu-Cheng ('oil disease') children prenatally exposed to heat-degraded PCBs. JAMA 268: 3213-3218

Coblentz A, Martel A, Ignazi G (1990) Effects of fetal exposition to aircraft noise on the birthweight of children. Proc Human Factors Society 34th annual meeting, California, 562-566

Cohen S, Weinstein N (1981) Nonauditory effects of noise on behavior and health. J Soc Issues 37: 36-61

DeCaprio AP, Tarbell AM, Bott A, Wagemaker DL, Williams RL, O'Hehir CM (2000) Routine analysis of 101 polychlorinated biphenyl congeners in human serum by parallel dual-column gas chromatography with electron capture detection. J Anal Toxicol 24: 403-420

DeJoy DM (1984) The nonauditory effects of noise: review and perspectives for research. J Aud Res 24: 123-150

Denham M, Schell LM, Deane G, Gallo MV, Ravenscroft J, DeCaprio A, The Akwesasne Task Force on the Environment (2005) Relationship of lead, mercury, mirex, dichlorodiphenyldichloroethylene, hexachlorobenzene, and polychlorinated biphenyls to timing of menarche among akwesasne mohawk girls. Pediatrics 115: e127-e134

Evans GW, Bullinger M, Hygge S (1998) Chronic noise exposure and physiological response: a prospective study of children living under environmental stress. Psychol Sci 9: 75-77

Fein GG, Jacobson JL, Jacobson SW, Schwartz PM, Dowler JK (1984) Prenatal exposure to polychlorinated biphenyls: effects on birth size and gestational age. J Pediatr 105: 315320

Fitzgerald EF, Deres DA, Hwang SA, Bush B, Yang BZ, Tarbell A, Jacobs A (1999) Local fish consumption and serum PCB concentrations among Mohawk men at Akwesasne. Environ Res 80: S97-S103

Fitzgerald EF, Hwang SA, Bush B, Cook K, Worswick Priscilla (1998) Fish consumption and breast milk PCB concentrations among Mohawk women at Akwesasne. Am J Epidemiol 148: 164-172

Frisancho AR, Ryan AS (1991) Decreased stature associated with moderate blood lead concentrations in MexicanAmerican children. Am J Clin Nutr 54: 516-519

Gallo MV, Schell LM, Akwesasne Task Force On The Environment (2005) Height, weight and body mass index among Akwesasne Mohawk youth. Am J Hum Biol 17: 269-279

Geber WF (1973) Inhibition of fetal osteogenesis by maternal noise stress. Fed Proc 32: 2101-2104

Geber WF, Anderson TA, Van Dyne B (1966) Physiologic responses of the albino rat to chronic noise stress. Arch Environ Health 12: 751-754

Glorig A (1971) Non-auditory effects of noise exposure. J Sound Vib 5: 28-29

Guo YL, Lin CJ, Yao WJ, Ryan JJ, Hsu CC (1994) Musculoskeletal changes in children prenatally exposed to polychlorinated biphenyls and related compounds (YuCheng children). J Toxicol Environ Health 41: 83-93

Guo YLL, Lai TJ, Ju SH, Chen YC, Hsu CC (1993) Sexual developments and biological findings in Yu-Cheng children. Organohalogen Compounds 14: 235-238

Guo YL, Lambert GH, Hsu CC (1995) Growth abnormalities in the population exposed in utero and early postnatally to polychlorinated biphenyls and dibenzofurans. Environ Health Perspect 103: 117-122

Hartikainen AL, Sorri M, Anttonen H, Tuimala R, Laara Esa (1994) Effect of occupational noise on the course and outcome of pregnancy. Scand J Environ Health 20: 444-450

Hartikainen-Sorri AL, Kirkinen P, Sorri M, Anttonen H, Tuimala R (1991) No effect of experimental noise on human pregnancy. Obstet Gynecol 77: 611-615

Hernandez-Avila M, Peterson KE, Gonzalez-Cossio T, Sanin LH, Aro A, Schnaas L, Hu H (2002) Effect of maternal bone lead on length and head circumference of newborns and 1month-old infants. Arch Environ Health 57: 482-488

Herrington LP, Nelbach JH (1942) Relation of gland weights to growth and aging processes in rats exposed to certain environmental conditions. Endocrinol 30: 375-386

Ishi H, Yokobori K (1960) Experimental studies on teratogenic activity of noise stimulation. J Med Sci 9: 153-167

Iturrian WB, Fink GB (1968) Effect of noise in the animal house on seizure susceptibility and growth of mice. Lab Anim Care 18: 557-560

Johnston FE (1993) The enduring effects of environmental deprivation on growth and development. J Hum Ecol 4: 117-134

Johnston FE (1995) Environmental constraints on growth: extent and significance. In Hauspie R, Lindgren G, Falkner F eds. Essays on Auxology. Castlemead Publications, Welwyn Garden City, 375-386

Johnston FE, Low SM (1995) Children of the urban poor: the sociocultural environment of growth, development, and malnutrition in Guatemala City. Westview Press, Boulder, $\mathrm{CO}$

Karmaus W, Zhu X (2004) Maternal concentration of 
polychlorinated biphenyls and dichlorodiphenyl dichlorethylene and birth weight in Michigan fish eaters: a cohort study. Environ Health 3: 1

Kaul PP, Srivastava R, Srivastava SP, Kamboj M, Chand S (2002) Relationships of maternal blood lead and disorders of pregnancy to neonatal birthweight. Vet Hum Toxicol 44: 321-323

Kawada T (2004) The effect of noise on the health of children. J Nippon Med Sch 71: 5-10

Knipschild P, Meijer H, Salle H (1981) Aircraft noise and birth weight. Int Arch Occup Environ Health 48: 131-136

Kuratsune M (1976) Epidemiologic studies on Yusho. In Higuchi F ed. PCB Poisoning and Pollution. Academic Press, New York

Lilienfeld DE, Stolley PD (1994) Foundations of Epidemiology. Oxford University Press, Oxford

Masuda Y (2001) Fate of PCDF/PCB congeners and change of clinical symptoms in patients with Yusho PCB poisoning for 30 years. Chemosphere 43: 925-930

Michaud D, Miller S, Ferrarotto C, Keith S, Bowers W, Kumarathsan P, Marro L, Trivedi A (2005) Exposure to chronic noise and fractionated $\mathrm{X}$-ray radiation elicits biochemical changes and disrupts body weight gain in rat. Int J Radiat Biol 81: 299-307

Murai K, Okamura K, Tsuji H, Kajiwara E, Watanabe H, Akagi K, Fujishima M (1987) Thyroid function in "Yusho" patients exposed to polychlorinated biphenyls (PCB). Environ Res 44: 179-187

Odland JO, Nieboer E, Romanova N, Thomassen Y, Lund E (1999) Blood lead and cadmium and birth weight among sub-arctic and arctic populations of Norway and Russia. Acta Obst Gynecol Scand 78: 852-860

Osman K, Akesson A, Berglund M, Bremme K, Schutz A, Ask K, Vahter M (2000) Toxic and essential elements in placentas of Swedish women. Clin Biochem 33: 131-138

Patandin S, Koopman-Esseboom C, De Ridder MAJ, WeisglasKuperus N, Sauer PJJ (1998) Effects of environmental exposure to polychlorinated biphenyls and dioxins on birth size and growth in Dutch children. Pediatr Res 44: 538-545

Patandin S, Koopman-Esseboom C, Weisglas-Kuperus N, Sauer, PJJ (1997) Birth weight and growth in Dutch newborns exposed to background levels of PCBs and Dioxins. Organohalogen Compounds 34: 447-450

Rylander L, Stromberg U, Hagmar L (1996) Dietary intake of fish contaminated with persistent organochlorine compounds in relation to low birthweight. Scand J Work Environ Health 22: 260-266

Rylander L, Stromberg U, Hagmar L (2000) Lowered birth weight among infants born to women with a high intake of fish contaminated with persistent organochlorine compounds. Chemosphere 40: 1255-1262

Safe SH (1994) Polychlorinated biphenyls (PCBs): Environmental impact, biochemical and toxic responses, and implications for risk assessment. Crit Rev Toxicol 24: 87149
Schell LM (1982) The effects of chronic noise exposure on human prenatal growth. In Borms J, Hauspie R, Sand A, Susanne C, Hebbelinck M eds. Human Growth. Plenum Press, New York, 125-129

Schell LM (1984) Auxological epidemiology and the determination of the effects of noise on health. In Susanne C ed. Genetic and Environmental Factors during the Growth Period. Plenum Press, New York, 209-219

Schell LM (1991) Effects of pollutants on human prenatal and postnatal growth: noise, lead, polychlorinated compounds and toxic wastes. Yearb Phys Anthropol 34: 157-188

Schell LM (1997) Using patterns of child growth and development to assess communitywide effects of low-level exposure to toxic materials. In Johnson BL, Xintara C, Andrews JS eds. Hazardous waste: impact on human and ecological health. Princeton Scientific Publishing Co., Princeton, 478-483

Schell LM (1999) Human physical growth and exposure to toxicants: Lead and polychlorinated biphenyls. In Johnston FE, Eveleth PB, Zemel BS eds. Human Growth in Context. Smith-Gordon, London, 221-238

Schell LM, Denham M (2003) Environmental pollution in urban environments and human biology. Ann Rev Anthropol 32: 111-134

Schell LM, Gallo MV, DeCaprio AP, Hubicki L, Denham M, Ravenscroft J, The Akwesasne Task Force on the Environment (2004) Thyroid function in relation to burden of PCBs, $p, p^{\prime}$-DDE, HCB, mirex and lead among Akwesasne Mohawk youth: a preliminary study. Environ Toxicol Pharmacol 18: 91-99

Schell LM, Hodges DC (1985) Longitudinal study of growth status and airport noise exposure. Am J Phys Anthropol 66: 383-389

Schell LM, Hubicki LA, DeCaprio AP, GalloMia V, Ravenscroft J, Tarbell A, Jacobs A, David D, Worswick P, Akwesasne Task Force On The Environment (2003) Organochlorines, lead, and mercury in Akwesasne Mohawk youth. Environ. Health Perspectives 111: 954-961

Schell LM, Knutson KL (2002) Environmental effects on growth. In Cameron $\mathrm{N}$ ed. Human Growth and Development. Academic Press, New York, 165-195

Schell LM, Madan M, Davidson GK (1992) Auxological epidemiology and methods for the study of effects of pollution. Acta Med Auxol 24: 181-188

Schell LM, Norelli RJ (1983) Airport noise exposure and the postnatal growth of children. Am J Phys Anthropol 61: 473-482

Schwartz J, Angle CR, Pitcher H (1986) Relationship between childhood blood lead levels and stature. Pediatrics 77: 281288

Selevan SG, Rice DC, Hogan KA, Euling SY, PfahlesHutchens A, Bethel J (2003) Blood lead concentration and delayed puberty in girls. N Engld J Med 348: 1527-1536

Srivastava S, Mehrotra PK, Srivastava SP, Tandon I, Siddiqui MK (2001) Blood lead and zinc in pregnant women and 
their offspring in intrauterine growth retardation cases. J Anal Toxicol 25: 461-465

Takahashi I, Kyo S (1968) Studies on the differences in adaptabilities to the noise environment in sexes and growing processes. J Anthropol Soc 76: 34-51

Tanner JM (1978) A concise history of growth studies from Buffon to Boas. In Falkner F, Tanner JM eds. Human growth, Vol. III, Nutrition and Nuerophysiology. Plenum, New York, 515-593

Tanner JM (1986) Growth as a mirror of the condition of society: secular trends and class distinctions. In Dubuc MB, Demirjian A eds. Human growth: a multidisciplinary review. Taylor and Francis, London

Taylor PR, Lawrence CE, Hwang HL, Paulson AS (1984) Polychlorinated biphenyls: influence on birthweight and gestation. Am J Public Health 74: 1153-1154

Taylor PR, Stelma JM, Lawrence CE (1989) The relation of polychlorinated biphenyls to birth weight and gestational age in the offspring of occupationally exposed mothers. Am J Epidemiol 129: 395-406

Tenenbaum DJ (1998) Northern overexposure. Environ Health Perspect 106: A64-A69

Uryu T, Hojo S, Kida A, Nishikawa M, Yoshinaga J (2004) Relationship between fetal lead exposure and birth weightevaluation using deciduous incisor enamel. Nippon Eiseigaku Zasshi 59: 387-394 [In Japanese]

Welch BL, Welch AM (1970) Physiological Effects of Noise. Plenum Press, New York

Wu T, Buck GM, Mendola P (2003) Blood lead levels and sexual maturation in U.S. Girls: the third national health and nutrition examination survey, 1988-1994. Environ Health Perspect 111: 737-741

Wu TN, Chen LJ, Lai JS, Ko GN, Shen CY, Chang PY (1996) Prospective study of noise exposure during pregnancy on birth weight. Am J Epidemiol 143: 792-796

Yen YY, Lan SJ, Ko YC, Chen CJ (1989) Follow-up study of reproductive hazards of multiparous women consuming PCBs-contaminated rice oil in Taiwan. Bull Environ Contam Toxicol 43: 647-655

Yen YY, Lan SJ, Yang CY, Wang HH, Chen CN, Hsieh CC (1994) Follow-up study of intrauterine growth of transplacental Yu-Cheng babies in Taiwan. Bull Environ Contam Toxicol 53: 633-641

Yoshimura T (1974) Epidemiological study on Yusho babies born to mothers who had consumed oil contaminated by PCB. Fukuoka Igaku Zasshi 65: 74-80 [In Japanese]

Zhan C, Lu Y, Li C, Wu Z, Long Y, Zhou L, Zhou B (1991) A study of textile noise influence on maternal function and embryo-growth. Hua Xi Yi Ke Da Xue Xue Bao 22: 394 398

Received: August 18, 2005

Accepted: October 12, 2005

Correspondence to: Lawrence M. Schell, A\&S 237, University at Albany, 1400 Washington Ave. Albany, NY 12222, USA

Phone: +1-518-442-4714

Fax: + 1-518-442-4563

e-mail: 1.schell@albany.edu 